\title{
ASPECTOS DA MINERAÇÃO E IMPACTOS DA EXPLORAÇÃO DE QUARTZITO EM PIRENÓPOLIS-GO
}

\author{
ASPECTS OF IMPACTS OF MINING AND EXPLORATION \\ QUARTZITE IN PIRENÓPOLIS-GO
}

\section{ASPECTOS DE IMPACTOS DE LA MINERIA Y EXPLORACIÓN CUARCITA EN PIRENÓPOLIS-GO}

\author{
Flávio Fernandes Faleiro, \\ Técnico em Geociências - Companhia de Pesquisa de Recursos Minerais \\ Serviço Geológico do Brasil (CPRM/SGB) \\ Rua 148, 485 Setor Marista, CEP: 74170-110, Goiânia - Goiás. \\ E-mail: ffaleiro@go.cprm.gov.br
}

Luciana Maria Lopes

Geóloga, Professora Adjunta do Programa de Pós-Graduação em Geografia - Instituto de Estudos SócioAmbientais / Universidade Federal de Goiás (IESA/UFG)

Campus Samambaia. Caixa Postal 131 / CEP: 74001-970, Goiânia - GO

E-mail: luciana@iesa.ufg.br

\section{Resumo}

O município de Pirenópolis-GO, juntamente com os municípios vizinhos (Corumbá e Cocalzinho), responde pela maior parte da produção mineral de quartzito ornamental do estado de Goiás. O quartizito, amplamente utilizado na construção civil como revestimento é, através do método de lavra em mina a céu aberto, extraído no município desde o período colonial, de forma rudimentar, por mão-de-obra familiar. Anterior a qualquer legislação que disciplina a atividade de mineração, a exploração de quartzito acumulou, ao longo de pouco mais de um século, um grande passivo ambiental devido à falta de aprimoramento técnico, organização e racionalização da atividade. O presente trabalho objetivou compreender os aspectos gerais da produção de quartzito e os principais impactos da atividade no município. Conclui-se que os principais impactos ambientais da mineração de quartzito relacionam-se à disposição de rejeitos atual e pretérita e ao risco à saúde do trabalhador, nas diversas etapas de produção. O presente trabalho justificou-se pela necessidade do conhecimento de realidades ambientais e sócio-econômicas oriundas da atividade da mineração do quartzito que, na região de Pirenópolis, responde por centenas de empregos diretos e indiretos.

Palavras-chave: Mineração, Quartzito, Pirenópolis-GO, Impactos.

\begin{abstract}
The municipality of Pirenópolis-GO, together with neighboring municipalities (Corumbá and Cocalzinho), accounts for most of the mineral production of ornamental quartzite of the state of Goias. The quartzite, used widely in construction as coating is, by mining method in the open pit, mined in the city since the colonial period, in a
\end{abstract}


rudimentary form, by hand-labor family. Before any legislation which regulates the activity of mining, the exploration of quartzite accumulated over little more than a century, a large environmental liabilities due to the lack of technical improvement, organization and rationalization of activity. This study aimed to understand the general aspects of the production of quartzite and the main impacts of the activity in the municipality. We conclude that the main environmental impacts of the mining of quartzite are related to the past and current disposal tailings and with risk to workers' health at various stages of production. This work was justified by the necessity of studying the environmental realities and socio-economic activity from mining of quartzite in the region of Pirenopolis, that answer by hundreds of direct and indirect jobs.

Keywords: Mining, Quartzite, Pirenópolis-GO, Impacts.

\section{Resumen}

El municipio de Pirenópolis-GO, junto con los municipios vecinos (Corumbá y Cocalzinho), representa la mayor parte de la producción minera de cuarcita ornamental del estado de Goiás La cuarcita, ampliamente utilizado en la construcción de edificios como cubierta es a través del método de minería en el pozo abierto, se explotan en la ciudad desde la época colonial, de una manera rudimentaria, por la familia de la manola mano de obra. Antes de cualquier legislación que regula la actividad de la minería, la cuarcita acumulado durante poco más de un siglo, los pasivos ambientales grandes debido a la falta de mejoras técnicas, la organización y la racionalización de la actividad. Este estudio tuvo como objetivo comprender los aspectos generales de la producción de cuarzo y los principales impactos de la actividad en el municipio. Se concluye que los principales impactos ambientales de la minería de cuarcita se refieren a la eliminación de escombreras y el pasado y el actual riesgo a la salud de los trabajadores en las distintas etapas de la producción. Este trabajo se justifica por la necesidad de estudiar las realidades del medio ambiente y la actividad socioeconómicos asociados a la minería de cuarcita en la región de Pirenópolis, contestada por centenares de puestos de trabajo directos e indirectos.

Palabras-clave: Minería, cuarcita, Pirenópolis-GO, Impactos.

\section{Introdução}

O município de Pirenópolis exibe patrimônio histórico-cultural nacionalmente conhecido além do que seus aspectos geológicos/geomorfológicos proporcionam cenários paisagísticos admiráveis conferindo ao município vocação turística que vem se intensificando. Em contrapartida, incongruente ao uso turístico, a geologia de Pirenópolis oferece potencialidades expressivas para a atividade de exploração de rochas ornamentais (quartzito) para uso na construção civil. As atividades de exploração do quartzito alicerçam a economia local impulsionada pelo expressivo número de 
empregos diretos e indiretos e divisas geradas ainda que a mineração ilegal seja fato comum.

Assim como qualquer atividade, a mineração apresenta seus pontos positivos e negativos que devem ser avaliados. Ela gera impactos, positivos e negativos, nas áreas social e ambiental. No social há que se considerar o desenvolvimento local que sinaliza avanços ou retrocessos. Nesse sentido, a atividade de mineração tem que ser feita de acordo com os parâmetros legais de forma a garantir uma exploração sustentável dos recursos naturais, com o mínimo de impacto, e preservando a saúde do trabalhador além de gerar, para o município, divisas que possibilitem sua aplicação em melhorias para a cidade e comunidade.

Quanto aos impactos ambientais, comuns quando não gerenciados, de modo geral provocam mudanças no relevo local através da retirada da cobertura vegetal, desmonte de rocha e armazenamento de minérios e de rejeitos. Tais operações impactam diretamente a vegetação e a hidrografia local, ou mesmo regional, podendo causar modificações no equilíbrio ecológico repercutindo no relevo, na biota, na qualidade do ar e da águas, ou seja, sobre todo o ambiente. A poluição da água e do ar são impactos extremamente importantes de serem diagnosticados e avaliados, uma vez que afetam diretamente a população local. A poluição do ar ocorre principalmente nas etapas de lavra, através dos desmontes, transporte de materiais e beneficiamento. A remoção da cobertura vegetal, o desenvolvimento da mina a céu aberto e a disposição dos rejeitos causam grandes impactos na paisagem.

$\mathrm{Na}$ exploração do quartzito de Pirenópolis são observados impactos que comprometem a qualidade paisagística, ambiental e social da área. Avanços, entretanto, estão ocorrendo. Com o advento das questões ambientais percebe-se movimento coletivo em prol de rearranjos produtivos no sentido da realização de trabalho de mineração mais eficiente, limpo, com menor passivo ambiental, legal e com maior retorno à sociedade. Prova disto é a preocupação com os rejeitos gerados e com alternativas para seu aproveitamento. Questões ligadas à saúde do trabalhador também tem suscitado alertas que despertam a comunidade para a importância do assunto.

A comercialização do quartzito atravessou fronteiras e hoje, além da sua venda no mercado brasileiro, vários países da Europa apreciam e compram as lajes de rara beleza e resistência. É chegada a hora de incorporar, à cultura extrativista local, os 
padrões de qualidade normalmente requeridos para exportação, que implicam numa exploração mineral social e economicamente sustentável.

Inicialmente se esclarece que, para exame dos impactos ambientais, foram analisadas as atividades de extração de quartzito na Pedreira da Prefeitura, no município de Pirenópolis, efetuando-se generalizações para as demais explorações do município.

O exemplo da exploração de quartzito em Pirenópolis possibilita o entendimento dos processos da atividade de mineração bem como o diagnóstico e prognóstico dos impactos inerentes a cada etapa da atividade.

Pautando-se nos exemplos das cavas exploradas na Pedreira da Prefeitura, o presente artigo visa compreender os aspectos gerais da produção de quartzito e os principais impactos ambientais da atividade no município de Pirenópolis-GO.

\section{Material e métodos}

\section{A área de Pesquisa}

A área de estudo é a "Pedreira da Prefeitura" que se situa no município de Pirenópolis, na mesorregião do leste goiano pertencente à microrregião do Entorno de Brasília. O município dista cerca de $120 \mathrm{~km}$ de Goiânia e $140 \mathrm{~km}$ de Brasília, localizando-se entre os paralelos $15^{\circ} 30^{\prime}$ e $16^{\circ} 10^{\prime} \mathrm{S}$ e os meridianos $48^{\circ} 50^{\prime}$ e $49^{\circ} 10^{\prime} \mathrm{W}$. Pirenópolis limita-se a nordeste com Cocalzinho de Goiás, a leste com Corumbá de Goiás, a sudeste com Abadiânia, ao sul com Anápolis, a sudoeste com Petrolina de Goiás, a oeste com Jaraguá e São Francisco de Goiás, a noroeste com Goianésia e ao norte com Vila Propício (Figura 1).

A área da Pedreira objeto de estudo, "Pedreira da Prefeitura", localiza-se a cerca de $4 \mathrm{~km}$ da área urbana de Pirenópolis, nos domínios do Grupo Canastra e na microbacia do Rio das Almas. O acesso é feito pela estrada que leva ao Pico dos Pireneus, na saída oeste da cidade (Figura 2). 


\section{Localização Pirenópolis - GO}

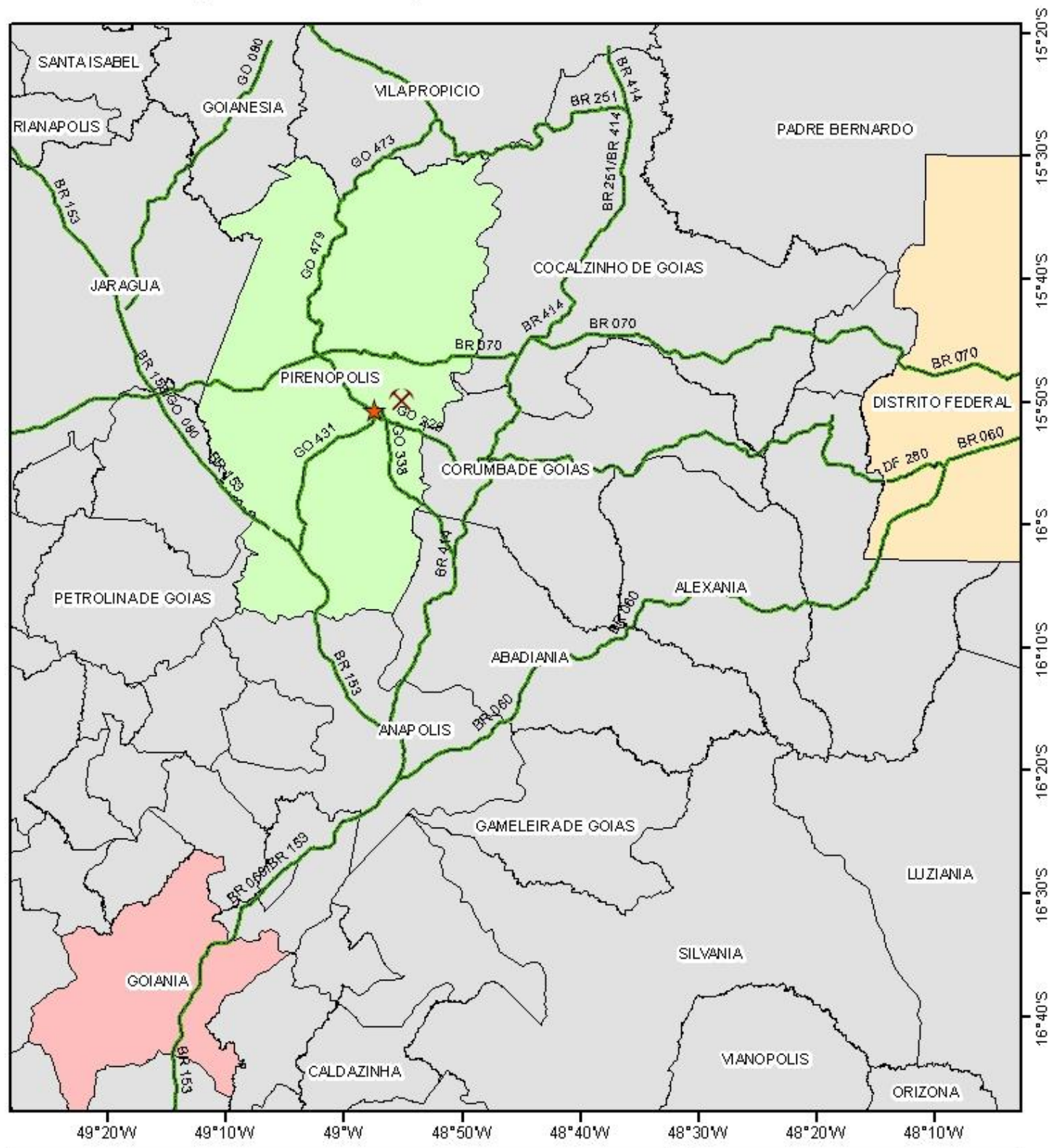

Fonte:
SIG-Goiás - Superintendência de Geologia e Mineraçẫo - SIC

Base de dados:

IBGE - censo 2007, limites a partir de bases cartográficas 1:100.000 Malha Vária atualizada a partir de imagens LandSat 7 de 2002/2003 SGM/SIC - AGETOP/SEINFRA

Projeçã̃o Transversa de Mercator - SAD 69 Zona 225

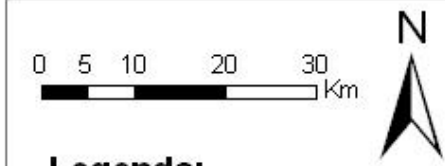

Legenda:

Х Pedreira da Prefeitura

th Sede Municipal

- Rodovias

Figura. 1 - Mapa de localização de Pirenópolis - GO. 


\section{Localização e Contexto Geológico - Pedreira Prefeitura}

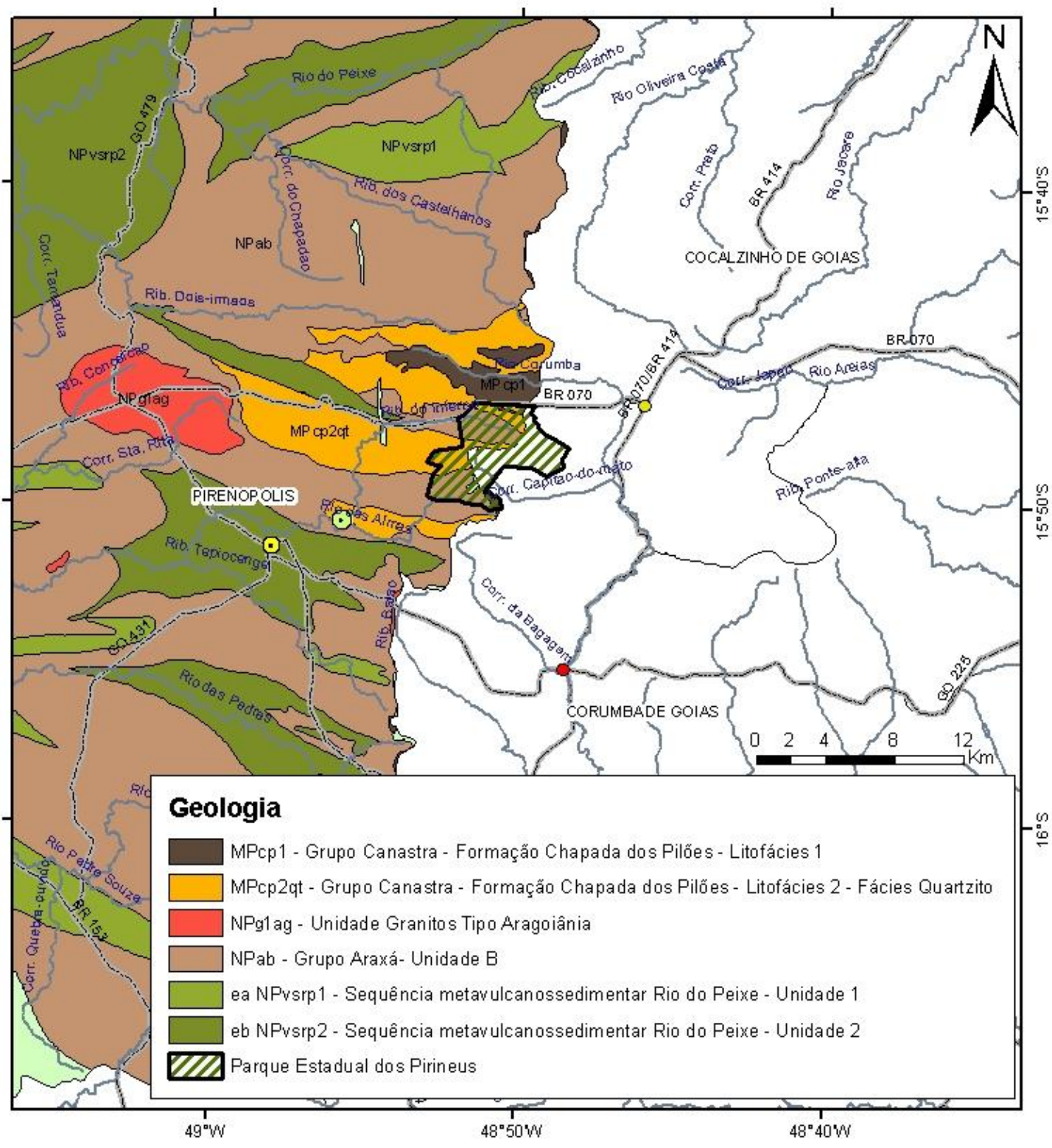

Fonte: SIG-Goiás - Superintendência de Geologia e Mineraçẫo - SIC

Base de dados:

IBGE - censo 2007, limites a partir de bases cartográficas 1:100.000 Malha Vária atualizada a partir de imagens LandSat 7 de 2002/2003 SGM/SIC - AGETOP/SEINFRA

MOREIRA, Maria Luiza Osório et al. Geologia do Estado de Goiás e do Distrito Federal. Escala 1:500.000. CPRM/SIC - FUNMINERAL 2008.

Projeção Transversa de Mercator - SAD 69 Zona 225

Elaboração: Flávio Fernandes Faleiro (2009)

\section{Legenda:}

- Pedreira da Prefeitura

- Pirenópolis

- Cocalzinho de Goiás

- Corumbá de Goiás

Drenagens

-..... Rodovias

Figura 2 - Mapa de localização e contexto geológico da Pedreira da Prefeitura. 


\section{Operacionalização}

A análise dos impactos da mineração envolve a compreensão das etapas que compõem a atividade e sua representatividade social e econômica, o que demandou pesquisa bibliográfica, documental e cartográfica de fontes diversas. Desta forma, o trabalho se pautou basicamente em levantamentos e coletas de dados, com validação do examinado em trabalhos de campo na área. As atividades compreenderam:

- Pesquisa teórica levantando as principais obras, referências, periódicos, monografias e trabalhos técnicos sobre o tema.

- Pesquisa em fontes secundárias: Documentos, Legislação, Zoneamentos Ecológicos-Econômicos, anuários estatísticos, censos.

- Pesquisa de campo: aferição dos problemas, entrevistas e registro fotográfico.

- Trabalho de Laboratório: elaboração de mapas com utilização de dados vetoriais (formato shapefile) por meio do aplicativo ArcGis 9.2.

$\mathrm{Na}$ etapa de produção, análise e interpretação dos dados foram elaborados quadros de impactos para cada etapa da mineração que, em conjunto com as observações de campo, permitiram determinar os principais impactos ambientais da atividade.

\section{Resultados e discussâo}

A atividade de mineração compreende basicamente as fases de Lavra (extração do mineral) e de Beneficiamento (tratamento do mineral), sendo estas compostas por diversas etapas. Com relação aos impactos ambientais da atividade constataram-se inicialmente diferentes impactos e em graus variados. Nas Fases I e II vários produtos, impactos e riscos resultam das etapas e procedimentos efetuados, o que é explicitado nos Quadros 1 e 2 a seguir. 


\begin{tabular}{|c|c|c|c|}
\hline${ }_{\mathrm{R}}^{(C-2) \mathrm{A}}$ & 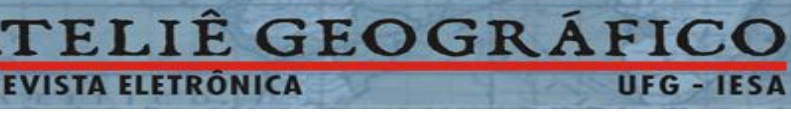 & \multicolumn{2}{|c|}{ ISSN: $1982-1956$} \\
\hline \multicolumn{4}{|c|}{$\begin{array}{ll} & \text { Fase I: LAVRA } \\
\end{array}$} \\
\hline Etapas & Procedimentos & Produtos & Impactos e Riscos \\
\hline $\begin{array}{l}\text { Decapeamento } \\
\text { e Desmonte }\end{array}$ & $\begin{array}{l}\text { - remoção da cobertura vegetal, das camadas estéreis e } \\
\text { do minério } \\
\text { - desmonte com ferramentas manuais, com tratores } \\
\text { e/ou com explosivos } \\
\text { - Dragagem de água do lençol freático do interior das } \\
\text { cavas }\end{array}$ & $\begin{array}{l}\text { - solo descoberto } \\
\text { - partículas } \\
\text { desagregadas } \\
\text { - topografia e } \\
\text { relevo modificado } \\
\text { - rejeitos } \\
\text { - minérios }\end{array}$ & $\begin{array}{l}\text { - aumento do escoamento superficial e diminuição da infiltração de } \\
\text { águas no solo; } \\
\text { - interferência na movimentação das águas de subsuperfície; } \\
\text { - rebaixamento do lençol freático } \\
\text { - processos erosivos } \\
\text { - transporte de partículas e assoreamento de drenagens; } \\
\text { - aumento de gases e partículas sólidas em suspensão. } \\
\text { - geração de ruídos e vibrações } \\
\text { - riscos a saúde do trabalhador } \\
\text { - remoção da vegetação, degradação paisagística } \\
\text { - supressão de fauna e flora; migração da fauna; atropelamento de } \\
\text { animais; desequilíbrios na biota aquática }\end{array}$ \\
\hline Transporte & $\begin{array}{l}\text { - utilização de caminhões, tratores ou carrinho de mão } \\
\text { - Minério: transportado para as serrarias na área } \\
\text { urbana de Pirenópolis ou para unidades de } \\
\text { beneficiamento manual na própria mina } \\
\text { - Rejeito: transportado para áreas de deposição }\end{array}$ & & $\begin{array}{l}\text { - emissão de gases e partículas sólidas } \\
\text { - riscos a saúde do trabalhador } \\
\text { - geração de ruídos e vibrações } \\
\text { - compactação e impermeabilização do solo }\end{array}$ \\
\hline $\begin{array}{l}\text { Disposição } \\
\text { Estéril }\end{array}$ & $\begin{array}{l}\text { - disposição em pilhas sem planejamento nas bordas } \\
\text { das cavas ou seu entorno }\end{array}$ & $\begin{array}{l}\text { - topografia } \\
\text { modificada }\end{array}$ & $\begin{array}{l}\text { - degradação paisagística. } \\
\text { - interferência no processo de escoamento de águas superficiais e de } \\
\text { subsuperfície. } \\
\text { - desmoronamentos, transporte de partículas e assoreamento de } \\
\text { drenagens } \\
\text { - inviabilização de exploração de reservas sobrepostas. } \\
\text { - partículas sólidas em suspensão }\end{array}$ \\
\hline
\end{tabular}

Quadro 1 - Impactos e riscos da mineração de quartzito na fase de lavra em Pirenópolis-GO. 


\begin{tabular}{|c|c|c|c|}
\hline \multicolumn{4}{|c|}{ Fase II: Beneficiamento } \\
\hline Etapas & Procedimentos & Produtos & Impactos e Riscos \\
\hline $\begin{array}{l}\text { Corte de } \\
\text { lajes }\end{array}$ & $\begin{array}{l}\text { - corte através de } \\
\text { equipamentos manuais } \\
\text { - corte através de discos } \\
\text { diamantados refrigerados } \\
\text { com água }\end{array}$ & $\begin{array}{l}\text { - rejeitos } \\
\text { - pó de serraria } \\
\text { - efluente } \\
\text { líquido com } \\
\text { partículas de } \\
\text { quartzito }\end{array}$ & $\begin{array}{l}\text { - partículas sólidas em suspensão } \\
\text { - geração de ruídos e vibrações } \\
\text { - pó de serraria (partículas de } \\
\text { quartzito) carreado para cursos de } \\
\text { água } \\
\text { - riscos à saúde do trabalhador e } \\
\text { de acidentes de trabalho } \\
\text { - geração de rejeitos } \\
\text { - degradação paisagística }\end{array}$ \\
\hline
\end{tabular}

Quadro 2 - Impactos e riscos da mineração no beneficiamento de quartzito em

Pirenópolis.

De todos os impactos, os de maior grau, conforme observado em campo, são aqueles relacionados à fase de lavra, incluindo a disposição do rejeito e a conseqüente degradação paisagística. A lavra do quartzito deixa marcas que, mesmo de longe, chamam a atenção pela degradação da paisagem, conforme pode ser observado na Figura 3.

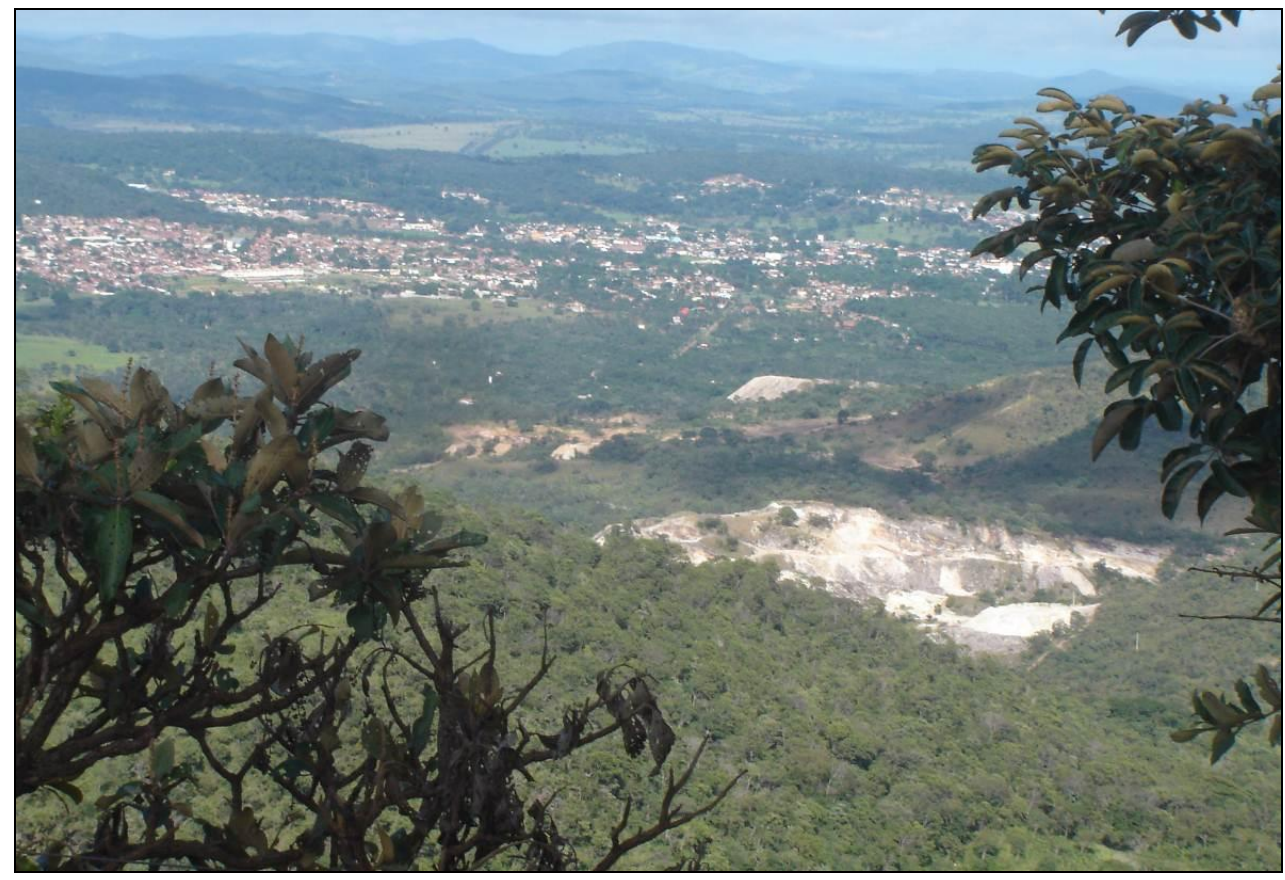

Figura 3 - Foto da degradação paisagística promovida pela lavra de Quartzito em Pirenópolis-GO. 


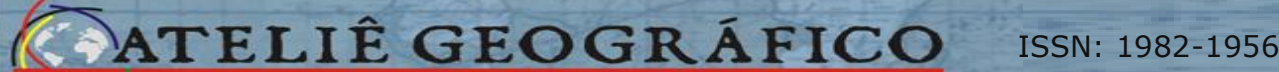 REVISTA ELETROONICA

Quanto ao rejeito, Barros (2002a), através de levantamento topográfico, avaliou 70 pilhas de rejeito em áreas da Pedreira da Prefeitura, por meio do dimensionamento de cada pilha. A realização do processo permitiu-lhe estimar um universo de $748.020 \mathrm{~m}^{3}$ de rejeitos. (Figura 4)

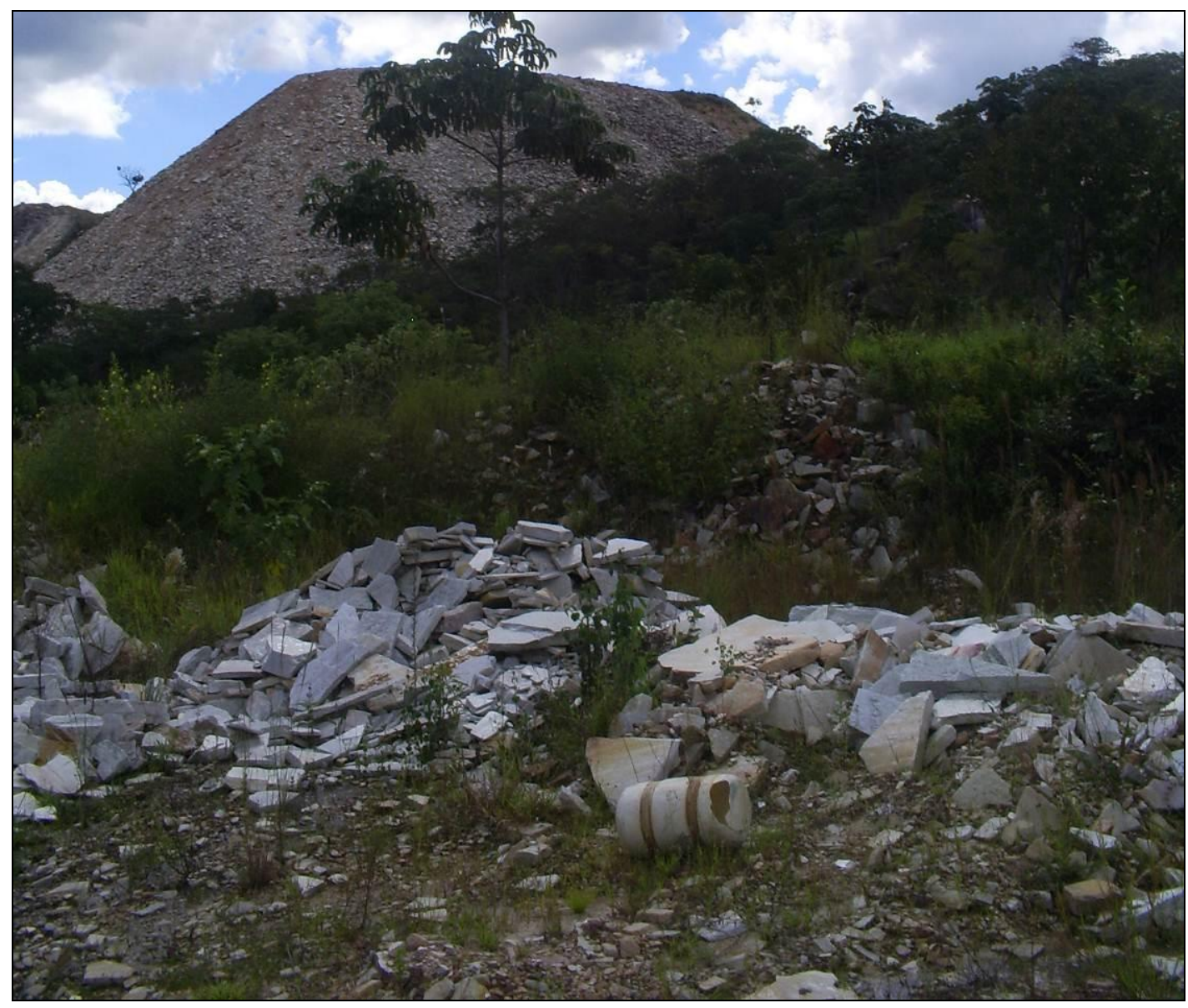

Figura. 4 - Foto das Pilhas de Rejeitos (no primeiro plano e ao fundo) na Pedreira da Prefeitura.

Segundo Barros (2002a), com aprimoramento de técnicas de desmonte a geração de rejeitos pode ser reduzida. A Pedreira da Prefeitura, segundo ele, tem cerca de 55\% de sua área recoberta por rejeitos e produz cerca de $375.000 \mathrm{~m}^{2}$ de lajes e $1.100 .000 \mathrm{~m}^{2}$ de retalhos ao ano. Tal produção é proveniente de apenas 140.000 toneladas das 400.000 toneladas de quartzito extraídas, ou seja, 260.000 toneladas do que é extraído é rejeitado o que representa, portanto, 65\% de perda. Segundo Barros (2002a, p.7), "o desmonte atualmente é feito com o uso de explosivos, sem qualquer assistência técnica, 
gerando grande quantidade de fraturas secundárias, o que reduz o tamanho das placas e gera mais resíduos".

No que se refere à disposição dos rejeitos de quartzito, o diagnóstico da AGIM (2002b, p.57) relata que "os rejeitos vêm sendo depositados há dezenas e dezenas de anos sem nenhum planejamento, em locais inadequados como em áreas a serem lavradas no futuro e nas bordas das pias, criando situações de risco".

Ao impacto paisagístico da Pedreira da Prefeitura somam-se os de inúmeras outras e os de serrarias que empilham e expõem as lajes de quartzito a céu aberto, causando poluição visual no âmbito da cidade e mesmo no campo nos locais onde são mineradas.

O transporte de sedimentos para os cursos d'água é também algo preocupante. Os sedimentos carreados podem provocar alterações na coloração das águas, tornandoas turvas e causando assoreamento dos leitos dos córregos o que modifica sua vazão e afeta os ecossistemas ribeirinhos. Do ponto de vista turístico, a presença de sedimentos em suspensão nos cursos d'água concorre para a degradação paisagística num município onde córregos, cachoeiras e praias fluviais constituem-se nos mais importantes atrativos.

Segundo Moreira et al. (2008) o município de Pirenópolis apresenta potencial moderado a alto para a exploração de rochas ornamentais, podendo ter um impacto grande na paisagem, fruto da exploração desordenada. A esse respeito, Barros (2002a, p.4) afirma que

\begin{abstract}
Apesar de sua importância econômica, a lavra do quartzito de Pirenópolis tem provocado manifestações de desagrado de parte da população da cidade e de órgãos ambientalistas por afetar a beleza cênica da cidade. Este aspecto é ainda mais sensível levando-se em conta a importância de Pirenópolis como município considerado patrimônio histórico e cultural causando ainda, prejuízos para o desenvolvimento do turismo, atividade crescente na região.
\end{abstract}

Impacto que merece destaque é o vinculado à saúde ocupacional e segurança do trabalhador. Em todas as etapas o trabalhador é submetido a riscos elevados no que diz respeito à sua saúde.

Devido às características do tipo de lavra (a céu aberto), os extratores de pedras estão o tempo todo submetidos à insolação. Além dos extratores de pedra, que cortam e amontoam as placas, existem os "chapas" que fazem o serviço de carga e descarga da produção. Ambos são submetidos a esforço físico intenso. 
Segundo a AMIP, as empresas fornecem Equipamentos de Proteção Individual EPI e exige dos empregados sua correta utilização, sendo que a maior dificuldade no uso de EPIs é a resistência por parte dos próprios funcionários.

O diagnóstico da AGIM (2002b, p.195) sintetiza os principais riscos a que estão sujeitos os trabalhadores no processo produtivo de quartzito:

riscos de possibilidade de acidentes na lavra como: cortes nas mãos e braços no manejo das pedras, desmoronamentos de taludes de frentes de lavras, desmoronamento de rejeitos situados à montante de pias em operação, no manejo de perfuratrizes, no manejo de explosivos, na operação com veículos e máquinas pesadas, desmoronamento das pilhas de bota-fora de rejeitos, na insalubridade geral da pedreira caracterizada por uma precariedade no abastecimento de água, abrigos para descanso, saneamento e assistência médica.

$\mathrm{Na}$ etapa de beneficiamento, que consiste no corte e serragem das placas, embora haja riscos de acidentes no manuseio de serras diamantadas, o maior problema enfrentado é a geração de particulados finos (de sílica) que, em suspensão podem ser inalados pelos trabalhadores, sujeitos a desenvolver, a longo prazo, doenças pulmonares como a silicose.

Definida pela Organização Internacional do Trabalho (OIT) como uma doença pulmonar causada pelo acúmulo de poeira nos pulmões, a silicose, segundo a FUNDACENTRO (2009), é uma doença irreversível, que só pode ser solucionada com transplante de pulmão. Segundo esta instituição "a silicose predispõe o organismo a uma série de co-morbidades, pulmonares e extra-pulmonares, como a tuberculose, o enfisema, a limitação crônica ao fluxo aéreo, as doenças auto-imunes e o câncer”.

Manchete de capa do Jornal O Popular, de 24 de maio de 2009, a silicose em Pirenópolis é descrita por Marcos (2009) como problema desconhecido pelas autoridades. De acordo com o texto do jornalista, a silicose causada pela inalação da sílica do quartzito incapacita e mata trabalhadores: "cada trabalhador envolvido com a atividade das pedreiras sabe contar a história de alguém que está doente ou que já morreu por causa do pó da pedra". Segundo a reportagem, a silicose é um problema quase desconhecido pelas autoridades e "não tem registro oficial específico de casos na saúde pública do estado". O único dado oficial conhecido é um número geral de 57 benefícios concedidos pelo Instituto Nacional de Seguridade Social - INSS, relacionados à silicose em todo o estado. E o repórter faz um alerta: "a reportagem 
contabilizou e conversou com seis doentes e teve notícias de outros três (...) identificou seis pessoas que morreram nos últimos anos. Todas tinham silicose".

Segundo a AMIP, as empresas apresentam crescente preocupação com os aspectos ambientais e com a saúde do trabalhador. O cenário da exploração hoje é outro. Segundo a associação, há uma maior organização da atividade.

\begin{abstract}
Os funcionários quando entram fazem exames de saúde admissionais e são monitorados fazendo novos exames de 6 em 6 meses. Dentre os exames são feitos o Raio-X do tórax, experimetria "que é o do pulmão, sopro" e o de audiometria, além do exame clínico (o ASO - Avaliação da Saúde Ocupacional). $\mathrm{O}$ médico indica se o funcionário está apto ou não a trabalhar indicando também, quando for o caso, a mudança de função. ( $\mathrm{Sr}^{\mathrm{a}}$. Marilda, secretária da AMIP).
\end{abstract}

Embora hajam melhorias significativas no processo produtivo, ainda existem trabalhadores com diagnóstico recente de silicose, conforme denuncia a reportagem de O Popular.

\title{
Considerações finais
}

Embora a mineração seja uma atividade de extrema importância na sócioeconomia de Pirenópolis, cabe ressaltar que gera significativos impactos ambientais inerentes à atividade. Os impactos, se não devidamente tratados, podem comprometer o bem estar social. Se por um lado gera divisas, emprego e renda, por outro lado degrada o ambiente, podendo comprometer outros setores da economia como o setor de serviços ligados ao turismo.

A racionalização da atividade de exploração mineral, assim como a mitigação e recuperação de áreas por ela degradadas, são atualmente alguns dos grandes desafios a serem superados almejando a compatibilidade da mineração com sua sustentabilidade. A exploração de quartzito necessita ser melhor planejada, necessita de ações de políticas públicas, monitoramento, fiscalização e investimentos em tecnologias, afim de acabar com as irregularidades, aumentando o retorno social da atividade através da tributação prevista em lei. Faz-se também necessário aumentar a eficiência da produção, minimizar e encontrar soluções de usos para os rejeitos. 
No que se refere à solução para a grande quantidade de rejeitos, nota-se que é necessária a racionalização de todo o processo de produção, com supervisão e orientação de técnicos habilitados, para que haja redução significativa de perdas, que atualmente giram em torno de $60 \%$. Pesquisas apontam para o aproveitamento do rejeito na geração de agregados para a construção civil. Embora estudos apresentem resultados satisfatórios para a produção de areia, o que se revela viável e potencializado pela proximidade de Pirenópolis com os centros consumidores de Goiânia/Anápolis/Brasília, ainda não existem usinas implementadas necessitando-se, portanto, de incentivos e fomento das instituições públicas para implementação de tais unidades de produção de areia. Esta é uma atividade duplamente compensadora porque, além do aproveitamento do rejeito para produção de areia, evita-se sua retirada dos leitos e das planícies de córregos e rios, atividade altamente impactante e, cada vez, mais inviável, apesar de ainda praticada.

A sociedade em geral possui uma visão deturpada da mineração considerando-a apenas como atividade altamente agressora ao meio ambiente, não refletindo sobre os seus aspectos positivos ou até mesmo sobre a dimensão de seus impactos quando comparados com os de outras atividades. A agropecuária, por exemplo, cuja fronteira só tende a aumentar, impacta vastas áreas e envolve o desmatamento, pode modificar a estrutura e capacidade de infiltração da água no solo, causar erosão, além do emprego inescrupuloso de defensivos agrícolas, que pode gerar danos diversos. A mineração se dá de forma localizada e, caso adequadamente conduzida, gera mais benefícios do que danos.

A mineração de quartzito apresenta valor histórico, sendo base de sustento de muitas famílias ao longo de décadas. O que se apresenta aos olhos de muitos como uma atividade de grande impacto, inclusive paisagístico, aos olhos dos que possuem sua história e de sua família atrelada à atividade traduz-se em algo com significado econômico, histórico e cultural.

Para que haja mitigação dos impactos negativos gerados, as instituições públicas que representam a sociedade devem cumprir o papel de fiscalizar e fazer cumprir a legislação cabível. Com o cumprimento integral da lei é possível melhorar o desempenho da mineração, maximizando a contribuição da atividade para o bem estar social. 
Referências

Agência Goiana de Desenvolvimento Industrial e Mineral - AGIM. Diagnóstico do Setor Mineral Goiano. Convênio MME/SMM/DNPM/AGIM, Goiânia, 2002. 137 p.

Diagnóstico Mineral e Ambiental das Áreas de Extração de Quartzito Ornamental da Pedreira da Prefeitura, Município de Pirenópolis, Goiás. Convênio n 008/2001 MME/SMM/DNPM/AGIM, Goiânia, 2002. 202 p. Volume 1.

BARROS, Tércio Pina de. Definição da Geometria e Distribuição dos Depósitos de Quartzito Ornamental na Região de Pirenópolis - GO. Convênio n ${ }^{\circ}$ 008/2001MME/DNPM/AGIM. Goiânia, 2002a. 53 p.

Difusão de Tecnologia para aproveitamento dos rejeitos granulados de lavra de quartzito ornamental na região de Pirenópolis - GO. Convênio $\mathrm{n}^{\circ}$ 008/2001-MME/DNPM/AGIM. Goiânia, 2002b. 76 p.

Projeto Difusão de Tecnologia Mineral Para Obtenção de Novos Produtos a Partir dos Rejeitos Granulados de Quartzito Ornamental na Região de Pirenópolis - GO - Estudo De Viabilidade Técnico-Econômica de Produção de Agregados - Ensaios de Produção de "Petit Pavê" - Convênio n n 008/2001MME/DNPM/AGIM. Goiânia, 2002c. 127 p.

FUNDACENTRO, Ministério do Trabalho e Emprego - MTE. Portal da Saúde e Segurança do Trabalhador. Sílica e Silicose. Disponível em: <http://www.fundacentro.gov.br/index.asp?D=SES> Acesso em: 31 jul. 2009.

MARCOS, Almiro. Silicose, Mal Silencioso em Pirenópolis. O Popular, Goiânia, 24 maio 2009. Capa, p. 4-5.

MOREIRA, Maria Luiza Osório et al. Geologia do Estado de Goiás e do Distrito Federal. Escala 1:500.000. CPRM/SIC - FUNMINERAL, 2008. 